\title{
El aprendizaje y la enseñanza del español a través de su historia lingüística: puesta en práctica y valoración en una clase de estudiantes francófonos (nivel B2+/C1)
}

Elena Díez del Corral Arteta

Université de Lausanne

Recibido: 19 enero 2014 / Aceptado: 6 octubre 2014

ISSN: 1697-7467

\begin{abstract}
RESUMEN: Este trabajo explora las posibilidades que ofrece la historia lingüistica en el proceso de aprendizaje de una lengua extranjera. La utilidad de esta subdisciplina lingüística es analizada a través de una puesta en práctica en una clase de estudiantes francófonos universitarios (nivel B2 + C1) en Suiza. Con ella se pretende resaltar, además, la importancia del conocimiento explícito en la adquisición de una segunda lengua.

Palabras clave: Historia lingüística, aprendizaje de español, enseñanza de español, conocimiento explícito.
\end{abstract}

The Learning and the Teaching of Spanish Through its Linguistic History: Implementation and valuation in a niversity class of francophone students (b2 / C1 level)

\begin{abstract}
The aim of this paper is to explore the possibilities of linguistic history in the process of learning a foreign language. The usefullness of this linguistic subdiscipline is analysed through an implementation in a university class of francophone students (B2+l C1 level) in Switzerland. It also highlights the importance of explicit knowledge in second language acquisition.

Key words: Linguistic history, learning Spanish, teaching Spanish, explicit knowledge
\end{abstract}

\section{INTRODUCCIÓN：LA HISTORIA LINGÜÍSTICA}

El estudio de la historia de la lengua como subdisciplina lingüística puede resultar arduo y complejo, sobre todo si se realiza desde un punto de vista interno, mediante el análisis evolutivo de una lengua como sistema. Esa historia interna se estudia a través de subdisciplinas como la Gramática histórica o la Lingüística histórica propiamente dicha.

La Lingüistica histórica investiga y describe la forma en que las lenguas cambian o mantienen su estructura a lo largo del tiempo (Bynon, 1981 [1977]: 13), es decir, constata los cambios producidos en la lengua, entendida como un sistema. Esta subdisciplina se ha llamado también Lingüística diacrónica, haciendo uso de la conocida oposición establecida por Ferdinand de Saussure (1919) entre sincronía (que considera la lengua desde un punto de vista estático, en un momento preciso de su historia) y diacronía (a través de la cual se entiende la lengua en su desarrollo a lo largo del tiempo, es decir, desde un punto de 
vista histórico). Por otro lado, la subdisciplina conocida como Gramática histórica suele emplearse también como sinónimo de estas dos, tal y como lo encontramos en el manual de Menéndez Pidal (1989), si bien se entiende el término 'gramática' en un sentido amplio, ya que abarca todos los niveles de análisis lingüístico (léxico, fonético y morfosintáctico).

Pero, además, existe otro tipo de historia - ya no interna- que concierne a los periodos de la historia de una lengua en relación con los contextos históricos y extralingüísticos en los que se emplea. Esta historia, conocida como historia externa, es la que interesa a la subdisciplina designada en los últimos años mediante el nombre de Historia lingüistica (Echenique y Sánchez Méndez 2005). En ella se ponen de relieve los acontecimientos históricos y literarios de cada época en relación con determinados fenómenos lingüísticos y aspectos internos. Este tipo de historia o subdisciplina lingüística es la que puede resultar, desde nuestro punto de vista, de gran utilidad e interés para los estudiantes de español como lengua extranjera, dado que suele resultarles más atractiva que la Gramática histórica. En ella se aborda un número elevado de datos históricos, literarios y culturales que repercuten y han influido notablemente en la conformación de la lengua española que están aprendiendo. Así, por ejemplo, existen explicaciones de carácter externo en relación con el gusto por el latinismo sintáctico y por la adopción de préstamos léxicos, asociados a menudo al prestigio y a la influencia política, económica o cultural de las comunidades de las que se toman (Torrens Álvarez, 2007: 17).

La falta de consideración sobre la utilidad de esta subdisciplina lingüística pone de manifiesto la necesidad de emprender proyectos que valoren las ventajas e inconvenientes de enseñar historia lingüística a los aprendientes de español como lengua extranjera. En otros sistemas universitarios diferentes al suizo, como, por ejemplo, en Norteamérica, ha tenido lugar también un debate sobre la utilidad de la enseñanza de la historia de la lengua española, tal y como se pone de relieve en Arteaga y Llorente (2005). No obstante, la reivindicación concreta de la enseñanza de la subdisciplina de historia lingüistica no ha sido puesta de manifiesto, por lo que hemos considerado preciso abordar un análisis que nos permitiera explorar las ventajas que puede aportar su aprendizaje al estudio del español como lengua extranjera.

Para llevar a cabo este objetivo, hemos puesto en práctica un curso de historia lingüística de 12 horas lectivas en un grupo de estudiantes universitarios de español de un nivel alto de usuario independiente (B2+) o competente (C1), siguiendo los niveles propuestos por el Marco de Referencia europeo para el aprendizaje, la enseñanza y la evaluación de lenguas extranjeras (MCERL). Para lograr aprobar el curso, los alumnos tenían que escribir un trabajo crítico-reflexivo en el que expusieran sus opiniones sobre la relevancia de las clases en su aprendizaje lingüístico. A través del análisis de estos trabajos podemos recopilar un conjunto de valoraciones que nos ofrecen una visión fundamental: la de los estudiantes expuestos directamente a este tipo de enseñanza.

Así pues, presentamos, en primer lugar, nuestro planteamiento de partida ( $(2)$; explicamos, seguidamente, cómo se programaron los cursos y cuáles eran las pautas que se ofrecieron para la elaboración de los trabajos ( $§ 3)$; para pasar, a continuación, a analizar los resultados obtenidos $(\S 4)$ y ofrecer, en última instancia, unas conclusiones con una visión retrospectiva y prospectiva del trabajo realizado $(\S 5)$. 


\section{Planteamiento de Partida: el conocimiento explícito}

Es de todos conocida la cantidad y variedad de factores que influyen en la adquisición y aprendizaje del español como lengua extranjera. Muchos investigadores en Adquisición de Segundas Lenguas (ASL) han demostrado en numerosas contribuciones cómo la edad, la metodología empleada, la aptitud del estudiante, la motivación, la cultura e incluso el sexo inciden en el aprendizaje de una segunda lengua (Bestard y Pérez 1992; Arnold y Brown 2000). Entre estos factores, se ha destacado también la relevancia del conocimiento explícito y cómo la instrucción formal favorece la elevación de la consciencia (EC) que repercute notablemente en el aprendizaje de una lengua extranjera, sobre todo en adultos (Ellis 1990, 1994).

Este conocimiento explícito puede desarrollarse a través de la asistencia a un curso de historia de la lengua, por lo que consideramos que es el factor más importante a tener en cuenta en la valoración de la utilidad de la historia lingüística para el aprendizaje del español como lengua extranjera. Así pues, la enseñanza de esta subdisciplina nos permite un aprendizaje de la lengua, entendido como proceso consciente que implica una internalización formal del lenguaje (Muñoz Liceras, 1992: 143). De este modo, el conocimiento explícito incide fundamentalmente en la motivación de los alumnos, despertando su curiosidad por el objeto de estudio en sí que están aprendiendo: la lengua española.

La utilidad del estudio histórico de la lengua española es notable para mejorar su conocimiento léxico, dado que les facilita, por ejemplo, la memorización de algunos vocablos. Así, para aquellos que posean conocimientos del latín y tengan como lengua materna una lengua romance - como sucede en el caso de nuestros estudiantes- el conocimiento de la evolución del grupo CL- latino les permitirá entender y memorizar todas esas palabras que evolucionaron a un sonido palatal lateral (llave) en español, mientras que en francés este sonido se mantuvo sin ningún tipo de alteración (clé). Del mismo modo, podrán entender cómo el español difiere en muchos vocablos del francés por, entre otras razones, los ocho siglos de dominación árabe de cuya lengua se adoptaron muchos términos.

Además, y por presentar otro caso concreto, autores, como Bravo Bosch (1994), han constatado cómo el aprendizaje de los meses del año o de los días de la semana puede resultar mucho más atractivo y, por tanto, más motivante, al conocer su historia en vez de memorizarlos únicamente como signos simples.

Así pues, el objetivo principal de este trabajo es explorar las posibilidades que ofrece la historia lingüística en el proceso de aprendizaje de una lengua extranjera a través de las opiniones de un conjunto de alumnos que han recibido una enseñanza de este tipo. Estos estudiantes son universitarios suizos que estudian la lengua española con el ánimo de especializarse en ella y obtener un título de grado similar al de Filología Hispánica en España (por el que, de hecho, puede convalidarse).

Para empezar nos planteamos algunas preguntas de investigación que responderemos en las conclusiones: 1) ¿consideran los estudiantes evaluados que el aprendizaje de la Historia lingüistica es útil para ellos?, 2) ¿por qué opinan los estudiantes que este es importante? ¿qué razones les inducen a afirmar que no lo es? y 3) ¿creen que los conocimientos que les aporta esta subdisciplina pueden influir en el aprendizaje del español como lengua extranjera? ¿de qué manera? 
Partimos de la idea de que acercarse a la historia del español proporciona al estudiante unas herramientas útiles para su comprensión y aprendizaje. El alumno adquiere una mayor conciencia de la lengua que está aprendiendo hasta el punto de que puede incluso influir en un aumento de su motivación y esta, como se ha demostrado en múltiples estudios de ASL, favorece el aprendizaje de una lengua extranjera.

Asimismo, a través del conocimiento de la historia de una segunda lengua se pueden entender muchas de las preguntas que afloran en el aprendizaje lingüístico, como las relacionadas con los orígenes de los vocablos, con su fonología, con las diferencias existentes con otras lenguas romances, etc. Su conocimiento, además, puede influir favorablemente en la consolidación del aprendizaje de algunas estructuras lingüísticas complejas para los estudiantes, como cita, por ejemplo, Torrens Álvarez (2007: 13-14) para la diferenciación entre las preposiciones de por o para y el uso entre los verbos ser y estar.

\section{Realización del CURSO: LAS ClaSes Y los tRABAJOS}

La historia de la lengua ha recibido una escasa atención en la enseñanza del español como lengua extranjera. Su aprendizaje no se contempla, por ejemplo, ni en el Plan Curricular del Instituto Cervantes ni en el MCERL. En este último se menciona únicamente la relevancia de la historia — sobre todo de sus personajes y de aquellos acontecimientos más representativos- dentro de las competencias generales del individuo y de los conocimientos socioculturales. En este sentido nos preguntamos si no sería más conveniente enseñar la historia de la lengua que se está aprendiendo, ya que su estudio integra no solo la historia per se sino también la historia lingüística.

No obstante, contamos con un manual específico para la formación de profesores de ELE, escrito por María Jesús Torrens Álvarez (2007). Para acercar la historia de la lengua a nuestros alumnos disponemos, por tanto, de esta obra y de un conjunto de fuentes y recursos a los que podemos acudir y que también ellos pueden consultar si las clases impartidas despiertan su interés. Existe una gran variedad de manuales generales y específicos de historia de la lengua, además de libros de ejercicios y, por supuesto, introducciones al comentario de textos diacrónicos y colecciones de textos adecuados para ello. Entre otros, cabe mencionar los célebres manuales de Historia de la Lengua de Menéndez Pidal (2005) y Lapesa (1981), así como otros estudios más recientes de historia de la lengua e historia lingüística realizados por algunos de sus discípulos como Cano Aguilar (1988; 2004), Echenique y Sánchez (2005) y Lleal (1990), entre otros.

La programación del curso de 12 horas lectivas se ha llevado a cabo teniendo en cuenta todos estos manuales y dividiendo el curso en una periodización que distingue 6 épocas: 1) la Hispania Antigua en la protohistoria europea, 2) la romanización, las invasiones germánicas y la conquista de los árabes, 3) el español de orígenes y los inicios de la Edad Media, 4) la Edad Media, 5) los Siglos de Oro y 6) el español moderno.

Una vez terminado el curso, los estudiantes debían escribir un trabajo crítico-reflexivo del curso. Este era uno de los requisitos indispensables para aprobar la asignatura, factor que condicionaba el esfuerzo de los alumnos, ya que todos deseaban aprobar u obtener una buena nota. Además, el trabajo valía un $40 \%$ de la calificación final del curso (un curso de 24 horas lectivas). Tenían, por tanto, la motivación necesaria para realizarlo bien. Además, 
desde el primer día de clase, se incidió en la importancia de este trabajo, pues el hecho de acometerlo debía condicionar desde el principio su actitud en la clase. Debían adoptar desde el primer momento una postura crítica ante las informaciones y conocimientos que estaban recibiendo, relacionándolos siempre con la relevancia de los mismos en su aprendizaje del español. Así pues, se insistió en cada clase del curso en que escribieran sus ideas después de cada una de las clases.

La descripción detallada de las indicaciones que se dieron a los alumnos para la elaboración del mencionado trabajo se recoge en los siguientes puntos:

1) El trabajo debe ser crítico y reflexivo con los conocimientos que les han sido impartidos en las clases. En él se debe analizar la utilidad de la enseñanza de la historia lingüística en relación con su aprendizaje lingüístico del español como segunda lengua. Para ello deben repasarse todos los contenidos ofrecidos e intentar responder a las siguientes cuestiones: ¿son útiles estos conocimientos? ¿Por qué sí? ¿Por qué no? Y ¿en qué sentido pueden favorecer o facilitar el aprendizaje lingüístico del español?

2) El trabajo es, por tanto, personal y deberá reflejar con claridad las ideas y opiniones que el estudiante tiene o ha adquirido al respecto. Se da cabida en él a todo tipo de apreciaciones, siempre y cuando estén bien argumentadas. No son válidas las afirmaciones del tipo: "este tema me ha parecido muy interesante y útil" si no van acompañadas de un porqué y de argumentos que fundamenten esas valoraciones.

3) Para la argumentación de esas ideas es conveniente y recomendable basarse en referencias bibliográficas (como los manuales de historia de la lengua que se han citado previamente).

4) La extensión mínima de los trabajos será de 7 caras en Times New Roman 12 con un espacio interlineado. Para su elaboración, además, se les entregará a los alumnos una hoja de estilo que pueden seguir como modelo. No obstante, se les dará flexibilidad para que empleen las normas que deseen, siempre y cuando estas sean aplicadas con homogeneidad a lo largo de todo el trabajo.

\section{Análisis de los resultados}

Analizamos a continuación las reflexiones extraídas de los trabajos de 5 alumnos que asistieron al curso de historia lingüística mencionado. Para respetar el anonimato llamamos a cada uno de ellos por un número: estudiante 1, estudiante 2 , estudiante 3 , estudiante 4 y estudiante 5 .

\subsection{Estudiante 1}

Este alumno se cuestiona una serie de preguntas interesantes respecto a la pertinencia de conocer la historia de una lengua y sobre todo de conocer lenguas muertas. "¿Qué interés puede tener aprender rasgos del lusitano? ¿Por qué no centrarnos mejor en aprender otros dialectos actuales y vivos como el murciano?» son preguntas que se formula. En ese sentido 
es crítico con las informaciones recibidas sobre las lenguas paleohispánicas y duda de la trascendencia de su aprendizaje, si bien en el siguiente apartado de su trabajo comenta el interés que le suscitaron estas lenguas al indagar en las fuentes e inscripciones que disponemos del celtibérico. De hecho, en su trabajo llega incluso a plantear una hipótesis sobre su extensión, ya que se han encontrado algunas inscripciones en una zona más oriental de la limitada área de influencia atribuida al celtibérico.

En un tercer apartado este estudiante se detiene en el problema de la periodización del español de orígenes. No se posiciona por ninguna de las posturas reseñadas en clase - la de Menéndez Pidal (1989) y la de Roger Wright (1988) — sino que se muestra escéptico con la idea de establecer una periodización y comenta la imposibilidad de conocer algunos datos históricos. Ese «misterio» en el desarrollo de la lengua le resulta, no obstante, atractivo, por lo que le motivan las incertidumbres que esta pone de relieve, sobre todo, en épocas primitivas. Ese interés quizás resida en que la enseñanza de esta índole no es categórica como otras, sino que da cabida a la formulación de hipótesis y de incógnitas como se suceden en la vida misma. Tendemos a simplificar a veces los problemas, cuando estos son en muchas ocasiones complejos y deberían explicarse tal y como nos enfrentamos a ellos.

En un cuarto subapartado, el alumno se centra en la época de orígenes y destaca el interés que esta clase tuvo para él, ya que opina que es importante conocer los textos que marcaron el inicio del romance castellano. Por ello, ha querido profundizar un poco más sobre los primeros textos literarios, es decir, sobre las glosas emilianenses y silenses, ya que le llamó la atención el hecho de que no se supieran con exactitud los dialectos que se representaban en ellas. En este sentido la duda es un aliciente más para documentarse, aunque al final de sus lecturas siga sin saber (como en el punto de partida) qué dialectos reflejan esos testimonios romances.

El quinto epígrafe lo dedica a la figura de Alfonso X, pues le gustó cómo se hablo de él en el aula y cómo la clase correspondiente se enfocó en las causas externas del cambio lingüístico, pues son estas las que le ayudan a entender cómo la lengua ha podido evolucionar. Esta percepción entronca precisamente con nuestra idea sobre enseñar Historia lingüistica en vez de Lingüistica histórica ( $c f r$. supra $\S 1$ ), luego la opinión de este alumno parece constatar que no estábamos tan equivocados en nuestros planteamientos iniciales.

En el apartado sexto, el alumno se detiene en estudiar el "castellano drecho", un término del que no se habló en clase, pero que apareció en sus lecturas para hacer el trabajo. Resulta relevante que el estudiante haya indagado sobre este término para conocer la variedad toledana que Alfonso X promulgaba en el momento en el que había que decantarse por un término frente a palabras ambiguas o regionales. De nuevo, un aspecto positivo a tener en cuenta sobre la motivación de este alumno por seguir conociendo más sobre la historia del español.

En sus conclusiones, sin embargo, parece contradecirse cuando comenta que en los estudios de historia de la lengua resulta desalentador que se traten de asegurar datos que no pueden definirse con total certeza.

\subsection{Estudiante 2}

La opinión de este estudiante respecto a la utilidad del aprendizaje de la historia de la lengua en la enseñanza de ELE es bastante crítica y negativa sobre todo en lo referente a algunas etapas. 
Sin embargo, considera que el aprendizaje de algunos rasgos resulta interesante y útil al aprendiente de español. Así, por ejemplo, cree que es importante acercarse a las lenguas prerromanas, previas a la latinización de la península, para entender la existencia de ciertos topónimos célticos, fenicios y griegos. También considera útil conocer el proceso de extensión del latín para poder comprender las diferencias que muestran el español con otras lenguas romances como el italiano y el francés. Además, le parecen importantes las informaciones ofrecidas sobre las invasiones germánicas y cree oportuno conocer los legados léxicos que nos dejaron para poder entender aspectos del actual léxico del español.

Asimismo, considera que la fragmentación del latín en diferentes dialectos nos ayuda a entender el plurilingüismo actual de España y que conocer la evolución de algunos sonidos nos permite entender el origen de las palabras y, por consiguiente, su significación. En ese sentido cree que la historia lingüística resulta de gran ayuda para el aprendizaje del español.

Sobre la lengua española empleada en los siglos XVI y XVII comenta la relevancia de explicar las normas ${ }^{1}$ castellana y andaluza, ya que existe todavía una diferencia entre ellas y, por tanto, una persona que aprende español debe conocerla. Además, considera fundamental saber los procesos de cambio que están todavía vigentes como, por ejemplo, el yeísmo y la pérdida de la - $\mathrm{d}$ - intervocálica, entre otros, para conocer de dónde proceden y por qué se originaron. Así pues, comenta de nuevo que estas características particulares familiarizan al estudiante con el extenso y complejo dominio hispanohablante, entendiendo la diversidad de variedades y hablas existentes. Por último, le parece apropiado conocer las reformas ortográficas de la Real Academia Española (RAE) y saber cómo esta institución fijó el uso de algunas grafías.

Tras estas notas, sin embargo, enumera una serie de cuestiones vistas en clase que no le parecen relevantes para el aprendizaje de la lengua española, aunque — señala - sea útil conocerlas en el ámbito lingüístico. Así pues, dice, por ejemplo, que algunos rasgos de las lenguas paleohispánicas no sirven al estudiante que tiene por objetivo aprender una lengua en sí misma y ser capaz de hablarla y escribirla. También comenta que el conocimiento de algunos parámetros y factores de influencia histórica en la lengua no son interesantes durante el aprendizaje de una lengua como el español. Apunta, por ejemplo, que muchos de los datos históricos aprendidos sirven únicamente para conocer el contexto en el que se habló el español, pero para nada más. Seguidamente, establece afirmaciones similares al comentar algunos datos literarios de los Siglos de Oro, pues considera que conocer todas esas informaciones históricas y literarias no resulta útil cuando el objetivo es aprender la lengua castellana.

En la última página de su trabajo, este estudiante vuelve a insistir en la necesidad de conocer fenómenos que existen todavía como el laísmo, leísmo y loísmo, pero concluye que la Historia lingüística puede ayudar mínimamente al aprendizaje del español. La considera útil para explicar las razones por las que la lengua ha llegado a ser como es en la actualidad, pero no para aprender una lengua de manera más eficaz o más fácilmente.

\footnotetext{
${ }^{1}$ Entendiendo la 'norma' como el conjunto habitual de usos fonéticos, gramaticales y léxicos que hacen los hablantes de una lengua determinada y no como un conjunto de reglas fonéticas, gramaticales y léxicas que delimitan el uso correcto de una lengua (Alvar 1984).
} 


\subsection{Estudiante 3}

El trabajo de este estudiante contrasta notablemente con el trabajo del estudiante 2 que acabamos de reseñar. Sus reflexiones, además, son de mayor profundidad y arguyen, en la mayoría de sus casos, la importancia del curso para el aprendizaje de la lengua española.

En el párrafo con el que inicia el trabajo este estudiante reflexiona sobre el aprendizaje de una lengua: «aprender una lengua es mucho más que aprender de memoria una lista de palabras o conocer la conjugación de los verbos irregulares. Aprender cualquier lengua es, sobre todo, entender la esencia de la lengua, sus cambios, su carácter y los acontecimientos internos y externos que la convirtieron en lo que es hoy para nosotros». Así pues, de entrada, parece que este estudiante tiene clara la utilidad del curso y lo refleja, además, de manera poética a través de una comparación del aprendizaje de la lengua (un ente vivo) con el conocimiento de una persona (un ser vivo). Opina que para comprender y entender a una persona hay que conocer los acontecimientos que han marcado su vida, su carácter e ir más allá de la personalidad que nos refleja a primera vista. Solo con esas informaciones podemos explicar, anticipar y comprender o entender el comportamiento de una persona y la idiosincrasia de una lengua.

No obstante, este estudiante se muestra crítico en el primer tema abordado, el de la protohistoria europea, ya que considera que no ayuda a comprender la lengua española o a proponer trucos mnemotécnicos para asimilarla. La importancia de esta etapa radica únicamente en la contextualización que nos ofrece de sus orígenes, pues más que servirnos para el aprendizaje de la lengua española como tal, nos permite conocer la etimología y el léxico importado de los diferentes pueblos que conquistaron España.

La comparación de textos del XIII con diferentes grafías, tratada en la clase dedicada a la época medieval, cree que resulta muy útil no solo para entender cómo se iba constituyendo el español, sino para acercarse también a otras lenguas procedentes del latín. Al conocer, por ejemplo, los cambios fonéticos y morfológicos que se produjeron en la etapa de orígenes del español, es más fácil aprender el portugués, dadas las similares evoluciones que muestran ambas lenguas en algunos aspectos.

Además, resalta la importancia de la asignatura en la toma de conciencia de la variedad de una lengua que sigue en constante evolución y cambio. Se sorprende de la velocidad a la que un idioma puede cambiar y se plantea cómo leerán nuestros textos dentro de doscientos años.

Por otro lado, pone de relieve la importancia de conocer la historia de las distintas variedades americanas, ya que considera que en los libros de didáctica de ELE, al menos en los manejados en las escuelas europeas, no se destacan estas variedades y se enseña únicamente la lengua hablada en España.

Asimismo, opina que al estudiar los cambios morfológicos de una lengua, se pueden adquirir medios mnemotécnicos para aprender la ortografía. Sin embargo, no especifica cuáles exactamente, aunque afirma que los francófonos también deberían saber más sobre la historia del francés para conocer mejor su gramática y su ortografía. Además, cree que es importante comparar el castellano con el francés, ya que al conocer los cambios producidos en determinados momentos de la historia se puede adivinar cómo va a ser o evolucionar una palabra. En este caso, sí expone un ejemplo sobre la diptongación de las vocales breves latinas, gracias a las cuales entiende que en francés se diga porte, en italiano porta y en 
español puerta. Así pues, afirma que el curso le ha proporcionado recursos para aprender otras lenguas romances y que, gracias a él, tiene la impresión de tener las claves para aprender el portugués o mejorar sus conocimientos en catalán.

Otra utilidad del curso la constata al acercarse de nuevo a la literatura del Siglo de Oro que, en otras ocasiones, no había logrado entender. Tras este curso, ha vuelto a leer algunas hojas y, sorprendentemente, cree que las entiende con más facilidad gracias al conocimiento de la historia de la lengua.

Como conclusión y recapitulación general manifiesta que el curso le ha sido útil y que le ha permitido reflexionar sobre la lengua, sobre lo que es y, sobre todo, sobre cómo poder mejorar su aprendizaje. A este respecto afirma de manera entusiasta que, a partir de ahora, cuando quiera conocer una lengua se aproximará a su historia lingüística para poder manejarla lo mejor posible.

\subsection{Estudiante 4}

Del trabajo de este estudiante se pueden extraer muy pocas observaciones, ya que no entendió correctamente el tipo de texto que se les pedía realizar y se detuvo en detalles que no tenían nada que ver con lo requerido para el trabajo.

No obstante, comenta que los orígenes del español le han acercado también a su lengua materna, dado que el castellano y el portugués compartieron muchos momentos históricos (como, los años de dominación árabe, por ejemplo).

También menciona de manera implícita la importancia de la historia externa y su repercusión lingüística al comentar las relaciones comerciales entre Italia y España durante el Renacimiento, y el léxico italiano que adoptó el español como consecuencia de ello.

\subsection{Estudiante 5}

El trabajo de este estudiante tampoco cumple el objetivo trazado, pues las críticas y valoraciones que realiza se limitan únicamente a las actitudes del profesor y a los contenidos impartidos, pero nunca a cuestionar la importancia de la historia lingüística en relación con el aprendizaje de una lengua en sí.

No obstante, en las conclusiones afirma que el curso le ha resultado instructivo como hablante no nativo del español, pues le ha permitido entender cómo la lengua está en constante evolución y cómo la adopción de extranjerismos o préstamos es un proceso infinito que llega hasta la actualidad con la abundancia de anglicismos que se incorporan a nuestro idioma.

\section{Conclusiones}

En primer lugar, cabe retomar las tres preguntas de investigación formuladas en $\S 2$ : 1) ¿Consideran los estudiantes evaluados que el aprendizaje de la Historia lingüística es útil para ellos?, 2) ¿Por qué opinan los estudiantes que la historia lingüistica es importante? ¿Qué razones les inducen a afirmar que no lo es? y 3) ¿Creen que los conocimientos que les aporta esta subdisciplina pueden influir en el aprendizaje de la lengua extranjera que se está aprendiendo? ¿de qué manera? 
Tras el análisis, podríamos responder a la primera y segunda pregunta, afirmando que los alumnos, en general, consideran la materia como útil o, al menos, algunos de los conocimientos vistos durante el curso.

Son varias las utilidades que se reseñan en el aprendizaje de la historia lingüística del español. Sin embargo, y respondiendo a la tercera pregunta, encontramos opiniones muy heterogéneas respecto a la utilidad que esta tiene en el aprendizaje de una lengua extranjera. Las valoraciones obtenidas, en última instancia, dependen en gran medida de la concepción que tenga cada estudiante sobre lo que implica aprender una lengua extranjera. El estudiante 3 , por ejemplo, tiene un concepto más humanístico y amplio del aprendizaje de una lengua que el estudiante 2, quien adopta una postura más práctica e instrumental, lo que condiciona su visión sobre la relevancia de la historia lingüística en su aprendizaje lingüístico.

A modo de síntesis recogemos las ideas más relevantes por las que los estudiantes consideran que la enseñanza de esta materia es útil:

1) porque facilita la lectura de textos de otras épocas, como los del Siglo de Oro (estudiante 3 ),

2) porque permite entender la lengua en su variación no sólo diacrónica, sino también diafásica, diastrática y diatópica (estudiante 1, estudiante 2, estudiante 3 y estudiante 4),

3) porque nos enseña la procedencia de varios topónimos existentes y de muchos términos léxicos todavía vigentes (estudiante 2, estudiante 3 y estudiante 4),

4) porque nos anima y nos facilita el aprendizaje de otras lenguas romances relacionadas con el español y su evolución (estudiante 2, estudiante 3 y estudiante 4),

5) porque nos permite conocer procesos de cambio actuales como el yeísmo o la pérdida de la -d-intervocálica y nos acerca a fenómenos como el leísmo, loísmo y laísmo (estudiante 2),

6) porque nos permite conocer el carácter de una lengua y los acontecimientos internos y externos que la han configurado (estudiante 3),

7) porque favorece la reflexión lingüística y la toma de conciencia sobre el aprendizaje de una lengua y sus particularidades (estudiante 3),

8) porque conociéndola, podemos entender también el plurilingüismo actual de España (estudiante 2),

9) porque estas enseñanzas permiten formularse hipótesis e incógnitas como las que nos encontramos diariamente en nuestra vida (estudiante 1).

Tras todo esto podemos afirmar que gracias a la historia lingüística, el alumno adquiere una mayor conciencia de la lengua que está aprendiendo - como se percibe en sus reflexiones-, hasta el punto de que creemos que puede incluso influir en un aumento de su motivación, incluso para aprender otras lenguas (como comenta el estudiante 3).

Asimismo, gracias al conocimiento de la historia de una segunda lengua se pueden entender muchas de las preguntas que afloran en el aprendizaje lingüístico como el relacionado con los orígenes de los vocablos, con su fonología, con las diferencias existentes con otras lenguas romances, etc. A este respecto, se ha puesto de relieve también cómo esta subdisciplina permite resolver muchas más cuestiones si el estudiante tiene como lengua nativa una lengua romance como el francés. 
A pesar de los resultados obtenidos, debemos ser cautos a la hora de establecer conclusiones, ya que somos conscientes de la probable influencia que las ideas del profesor hayan podido ocasionar en las opiniones de los alumnos. En este sentido encontramos limitaciones en la investigación y no podemos verificar con precisión la pertinencia de la enseñanza de la historia de una lengua para el aprendizaje de una segunda lengua, ya que nos basamos en las percepciones de unos estudiantes que a veces están condicionados por el medio en el que escriben y por el contexto en el que han recibido esas clases. Además, algunos no entienden qué es exactamente lo que se les pedía y realizan trabajos de otra índole, pues no están acostumbrados a escribir textos críticos y reflexivos, a pesar de estar en la universidad.

El alcance de este trabajo reside en poner de relieve que existe, al menos, alguna utilidad (sea esta a gran o pequeña escala) de la historia lingüística en el aprendizaje del español como lengua extranjera, tal y como se manifiesta en las opiniones de algunos estudiantes. Otra de las limitaciones del mismo estriba en la escasez de datos recopilados, ya que se han analizado únicamente 5 trabajos de los cuales solo 2 han comprendido a la perfección lo que se les pedía hacer. Para evitar comentarios vacíos por parte de los estudiantes sería recomendable introducir algunas mejoras en la recopilación de datos como, por ejemplo, la elaboración de una encuesta o guía más específica con algunas preguntas que facilitaran la reflexión a los alumnos sobre cada uno de los aspectos que se van a tratar en clase, para que no tuvieran que enfrentarse directamente con la escritura de un trabajo crítico al que no están acostumbrados.

Por todo ello, es necesario seguir evaluando la opinión de los alumnos tras la asistencia a un curso de historia lingüística para poder ofrecer generalizaciones de más valor científico. En ese sentido, tomamos esta investigación como punto de partida de un proyecto más extenso.

\section{REFERENCIAS BIBLIOGRÁFICAS}

Alvar, M. (1984). La lengua como libertad. Las Palmas de Gran Canaria: Cabildo Insular de Gran Canaria.

Arnold, J. y Brown, H. D. (2000). "Mapa del terreno", in Arnold J. (ed.). La dimensión afectiva en el aprendizaje de idiomas. Cambridge: University Press, 19-41.

Arteaga, D. L. y Llorente, L. I. (2005). Los cursos de historia del español ¿son cosas del pasado?, in FIAPE. I Congreso internacional: El español, lengua del futuro. Toledo, 20-23/03-2005.

Bestard Monroig, J. y Pérez Martín, M.C. (1992). "Factores que influyen en el aprendizaje de una segunda lengua", in La didáctica de la lengua inglesa. Madrid: Síntesis, 33-40.

Bynon, T. (1981 [1977]). Lingüistica Histórica. Madrid: Gredos. Versión española de José L. Melena.

Bravo Bosch, M. C. (1994). "Introducción de la historia de la lengua en la clase de gramática", in ASELE, Actas IV, 391-397.

Cano Aguilar, R. (1988). El español a través de los tiempos. Madrid: Arco/Libros.

Cano Aguilar, R. (ed.) (2004). Historia de la lengua española. Barcelona: Ariel.

Echenique Elizondo, M. T. y Sánchez Méndez, J. (2005). Las lenguas de un reino. Historia lingüistica hispánica. Madrid: Gredos.

Ellis, R. (1990). Instructed Second Language Acquisition. Oxford: Blackwell.

Ellis, R. (1994). The Study of Second Language Acquisition. Oxford: OUP.

Lapesa, R. (1981). Historia de la lengua española. Madrid: Gredos.

Lleal Galceran, C. (1990). La formación de las lenguas romances peninsulares. Barcelona: Barcanova. 
Menéndez Pidal, R. (1989). Manual de gramática história española. Madrid: Espasa-Calpe.

Menéndez Pidal, R. (2005). Historia de la lengua española. Madrid: Fundación Ramón Menéndez Pidal.

Muñoz Liceras, J. (1992). La adquisición de las lenguas extranjeras. Madrid: Visor.

Saussure, F. (1919). Cours de Linguistique Générale. Paris: Payot.

Torrens Álvarez, M. J. (2007). Evolución e historia de la lengua española. Madrid: Arco/Libros.

Wright, R. (1988). Latín tardio y romance temprano en España y la Francia carolingia. Madrid: Gredos. 